\title{
TAX CHALLENGES IN THE COLLABORATIVE ECONOMY
}

\author{
Maris Juruss ${ }^{1}$, Dr.oec, , asoc. professor; Justina Hudenko ${ }^{1}$ Dr.oec,, asis. professor and Ilze \\ Varlamova ${ }^{1}, \mathrm{Mg}$. oec. \\ ${ }^{1}$ Riga Technical University, Latvia
}

\begin{abstract}
A variety of collaborative economy business models are rapidly emerging and growing across the world, calling for changes in traditional tax policies. Although the collaborative economy shows a rapid growth, the review of the existing taxation practices within the collaborative economy reveals inefficiency, associated mainly with the blurred boundaries among professional and non-professional service providers, with the avoidance to cooperate from collaborative platforms and with the fragmentation in taxation regimes among EU member states and worldwide. The aim of this paper is to investigate tax challenges arising from the collaborative economy and to offer a comprehensive model of the tax system development in the collaborative economy. Accordingly, this paper demonstrates the results of systematization of the collected task-oriented data and the description of the proposed model developed by the generalisation approach. Data collection and systematization methods have been used. The authors conclude that the taxation of the collaborative economy must be investigated on the global level by using collaborative economy instruments (platforms and scoring). The role of awareness of both service providers and tax administrations is stressed in the discussion part.
\end{abstract}

Key words: collaborative economy, taxation, information exchange, peer-to-peer services, collaborative platforms.

Jel codes: $\mathrm{H} 21, \mathrm{H} 24, \mathrm{H} 25, \mathrm{~K} 34, \mathrm{H} 71$

\section{Introduction}

In a view of a technological progress, a new concept of cost sharing has become the central issue in many fields of the economy. This economic behaviour has become so popular that it has created a new concept - collaborative economy. In light of common digital cognition, it is becoming extremely difficult to ignore the shift from traditional business-to-peer (B2P) economy to peer-to-peer (P2P) and peer-to-business (P2B) forms (Butenko \& Larouche, 2015), as this new business model has high potential for the development. There is a growing body of literature that recognises the importance of taxation issues in this field and shows the increasing concern that tax administration is being disadvantaged for the time being.

This paper is aimed to investigate factors that determine an effective taxation in the collaborative economy and proposes a new model of the tax system development. The key issues addressed to tax policy makers in this paper are: a) prior notification about classification of service providers, distinguishing professionals from non-professionals; b) development of cooperation between collaborative platforms and tax administrations; and c) development of the common integrated tax system on EU or worldwide level. For these analysis, task-oriented data collection and systematization methods were used. A generalisation approach was utilised, integrating the addressed issues to establish a common model of the tax system development in the collaborative economy. Data collection, systematization methods and other scientific methods have been used for the specified tasks. The following tasks were completed: a) analysed the practices taken by EU countries to tackle the collaborative economy tax issues; b) measured the impact of new approach to deal with tax issues of collaborative economy.

This study was exploratory and interpretative in nature as there were relatively few historical studies and lack of statistics in this area. However, the study offers some important insights into the relations among actors and into aspects of the taxation system in the collaborative economy. Understanding these links will help to completely change the perception of taxation policy and encourage tax administrations to become the equal partners of the collaborative society. A full discussion of the specific taxation tool kit lies beyond the scope of this study. 
The paper has been divided into four parts. The first part provides quick insight into concepts and trends of collaborative economy, the second part investigates existing knowledge and practices in the taxation of collaborative economy, the third part describes the proposed model of tax system development in the collaborative economy and, finally, the last part discusses limitations of the research and provides recommendations for future studies and practical implementations. At the end of the paper the conclusions and recommendations are summarised in brief.

\section{The concept and trends of collaborative economy}

This part of the paper determines the concept of the collaborative economy, highlights its main actors and their economic relations in a view of the taxation needs as well as assesses the significance of this activity in present and future.

To be going on, here it is necessary to clarify exactly what is meant by collaborative economy. In the field of economy, various terms of the same concept are found. Bretta (2018) StanoevskaSlabeva et al. (2017) and many others used the term "sharing economy" to refer to the emerging taxation framework. Maselli et al. (2016) argued that "the definition of the sharing economy is precise, but somewhat restrictive" and used in their essay the term "on-demand economy". Other mutually substituTable terms used in this content are "peer-to-peer economy", "gig economy", "platform economy". Although Selloni (2017) made a synthetic overview of the mentioned terms highlighting their distinctions, throughout this paper, the term "collaborative economy" will be used to refer to all the "distributed networks of connected individuals and communities versus centralised institutions" (Botsman and Roger, 2010) as this particular term is used by the European Commission (2017).

The key actors of the collaborative economy can be listed as follows:

- persons, that share assets, resources, time and/or skills - service providers;

- users of the shared objects- users;

- intermediaries that connect them via an online platform - collaborative platforms.

The main discrepancy of the collaborative economy is that transactions generally do not involve a change of ownership, and can be executed P2P and P2B both for profit and not-for-profit (based on European Commission, 2018). To continue comparison of the odds between the collaborative and traditional economy for taxation needs we viewed it from several aspects of taxation system: a) the payer, b) the base, c) the rate, d) the application, e) the administration.

Practically any person who has an unused asset or unemployed time can engage in collaborative economy and earn income. This blurs the boundaries between professional provision of service and occasional (non-professional) "gig". Therefore, it is a challenge to identify a tax payer, as it does not have a continuous status (Petropoulos, 2017). In some countries, professional and non-professional activities are differentiated stating that professional activity is profit-oriented, whereas nonprofessional activity involves cost reduction (European Commission, 2016). In other countries, thresholds of income or activity's frequency are introduced to classify tax payers (Bozdoganoglu, 2017), therefore, narrowing a taxbase. This requires a continuous analysis of each actor's activity and a huge administrative resource. Moreover, if there is not a clear boundary between the employment status of a service provider, i.e. whether a person is an independent economic operator or an employee of the collaborative platform, it is resulting in tax rate determination problem (Petropoulos, 2017; Leighton, 2016). The technological progress has made it possible to connect demand and supply in a digital environment (collaborative platforms) quickly and efficiently. These platforms can be physically located in the distinct country from where they generate income from 
users' commissions for P2P transactions. According to the existing tax regulation, digital presence does not create the legal basis for the tax application, as a result, the collaborative platforms usually shift their residences to countries with lower tax rates, but act worldwide. Last, but not least, the massive number of small-scale activities are facilitated by the collaborative platforms resulting in negative cumulative impacts. Zale (2016) reported that scale is a defining feature and a fundamental challenge of the collaborative economy. Small-scale activities that once fit the criteria for light or No regulation are occurring at scales at which regulation makes sense.

The European Commission (2018) reveals that the collaborative economy has expanded in many fields of economy where the most popular sector is the finances. Most of the collaborative platforms are originated in the EU, but there are also 42 internationally operating platforms originated outside the EU (mainly in the United States) and operating in international markets (European Commission, 2018). The turnover of the collaborative economy in the EU was estimated EUR 26.5 billion (0.17\% of EU-28 GDP in 2016) and is expected to reach an average of EUR 160-572 billion in the future(Council of the European Union, 2017), where Estonia, Poland, Latvia, Luxembourg, the Czech Republic and Sweden perform above the EU-28 average, but in absolute numbers, France enjoys the largest collaborative economy market share in the EU (EUR 8.6 billion), followed by the UK (EUR 4.6 billion), Spain (EUR 2.7 billion) and Poland (EUR 2.7 billion) (European Commission, 2018). The European Commission (2018) has also reported that about 394,000 persons are employed within the collaborative economy in the EU-28 (0.15 \% of EU-28 employment).

The results in this part indicate that the number of collaborative platforms, service providers and users is likely to continue to rapidly increase in the next decade. This enables certain policymakers simply to forbid some services provided by the collaborative platforms, as it is done temporarily in Hamburg and Brussels for Uber or in Berlin for Airbnb, or contrary, to allow work at their will. Trends in the collaborative economy call for changes in tax system, considering significant differences stated between the taxation conditions in the traditional and the collaborative economies: uncertainty in a tax regime of tax payers, a huge scale of minor transactions, unpredictability of residency of collaborative platforms etc. The next part, therefore, moves on to discuss the necessary changes.

\section{Taxation practices in the collaborative economy}

This part of paper is aimed to review recent research and practices in the field of the taxation in the collaborative economy to pick up the best practices and to dismiss ineffective solutions.

Remeur (2018) based on the review provided by Codagnone et.al (2016) concluded that the literature on the collaborative economy does not address tax aspects in detail. She suggested that "dealing with taxation in the collaborative economy requires a case-by-base and tax-by-tax approach that prevents a straightforward 'one-size-fits-all' approach" and linked the collaborative economy and the digital business, as they share common features. This reflects the existing attitude to the fragmentation in the taxation of the collaborative economy. Several member states that have adopted measures to foster a tax compliance in this sector do this in distinct ways: Belgium, Denmark, Finland and France specify diverse thresholds, beyond which the profit is to be considered professional income and subject to tax; the tax authorities were granted the powers to obtain data from digital platforms in the United Kingdom; Slovakia and Hungary apply general taxation rules (European Parliament, 2018).

As it was mentioned, since the collaborative platforms provide intermediary services in a digital environment, it makes tax administration in their domestic market difficult, since collaborative platforms do not have a physical presence in the country where their users are. Therefore, as 
presented by Erwin \& Karaman (2017) the income generated in country's territory cannot be subject to income tax. Pantazatou (2018) considered that challenges of the collaborative economy are in the identifying of the taxpayers and the taxable income, as well as the lack of compliance and enforcements. She associated these challenges with the incoherent taxation of the collaborative economy at the Member State level and suggested the EU to take comprehensive action by adopting legislation that would establish general principles or guidelines for all Member States. Goudin (2016) also came to the similar conclusion.

Apart from the legislation tools, Rigaux (2016) confirmed the effectiveness of rising the awareness of users and service providers as well as of the development of the cooperation among tax administrations and collaboration platforms. For instance, the "Sharing Economy Tax Centre" has been set up to provide information on the application of taxes to the collaborative economy in Ireland. This approach can make sense, since Rahim et al. (2017) also has shown that service providers involved in the peer-to-peer model are not well informed of their tax risks.

In the places where tax administrations achieve cooperation with the collaborative platforms (Airbnb tourism tax - Paris, Amsterdam, Lisbon; Uber VAT- Spain, Sweden, Netherlands) they even undertake withholding and collecting taxes to the respective budget. Another cooperation practise emerged from collaborative platforms operating in the transport sector in Estonia. They transmit information about drivers' income to tax administrations which is automatically added to their tax declaration (Bozdoganoglu, 2017). However, the largest collaborative platforms (as Airbnb and Uber) operate in a collaborative economy by organization of the international holding company network which have subsidiaries in countries with the most favourable tax regimes (Petropoulos, 2017; O'Keefe \& Jones, 2015). In this way, international companies carry out the aggressive tax planning, which makes it possible to avoid taxes, reduce income tax base and shift profits to countries with lower tax rates (Karaman\& Erwin, 2017; McClure et al., 2016). On the other hand, only those collaborative platforms that have reached global scale are known to national tax administrations as they have reached wide resonance. Smaller platforms are used to be engaged in non-registered economic activity (Pantazatou, 2018).

Considering all of this evidence, it seems that the existing state of play outlines a critical role of users and service providers' awareness as well as the necessity to combat the territorial fragmentation of the taxation. It has emerged that tax administrations must study the effectiveness lessons from the collaborative society. The third part of the paper, therefore, moves on to discuss the model of the tax system development in the collaborative economy.

\section{The model of the tax system development in the collaborative economy}

The following part of this paper moves on to describe in greater detail the tax system development action model. The review of research and practices provided the set of three related significant clusters of emerging taxation system:

- service providers, that generate (or not) value added or personal (corporative) income, imply a corresponding tax liability and are the key element in the collaborative economy chain in terms of tax classification;

- collaborative platforms, that ensure that users and service providers make their activities, are the key element in terms of tax avoiding;

- tax administrations, considering absence of any physical boundaries in digital economy, are a key issue to the international collaboration in order to combat tax evasions in national economies. 
Taken together, these results suggest that the only effective solution of the tax system development towards the collaboration economy is integrating it in the collaborative society on these three levels. Figure 1 presents the model of tax system development in the collaborative economy: there are three levels of inclusions that require different actions of the actors. A brief description of each level is provided below the Figure developed by the authors.

Tax administrations

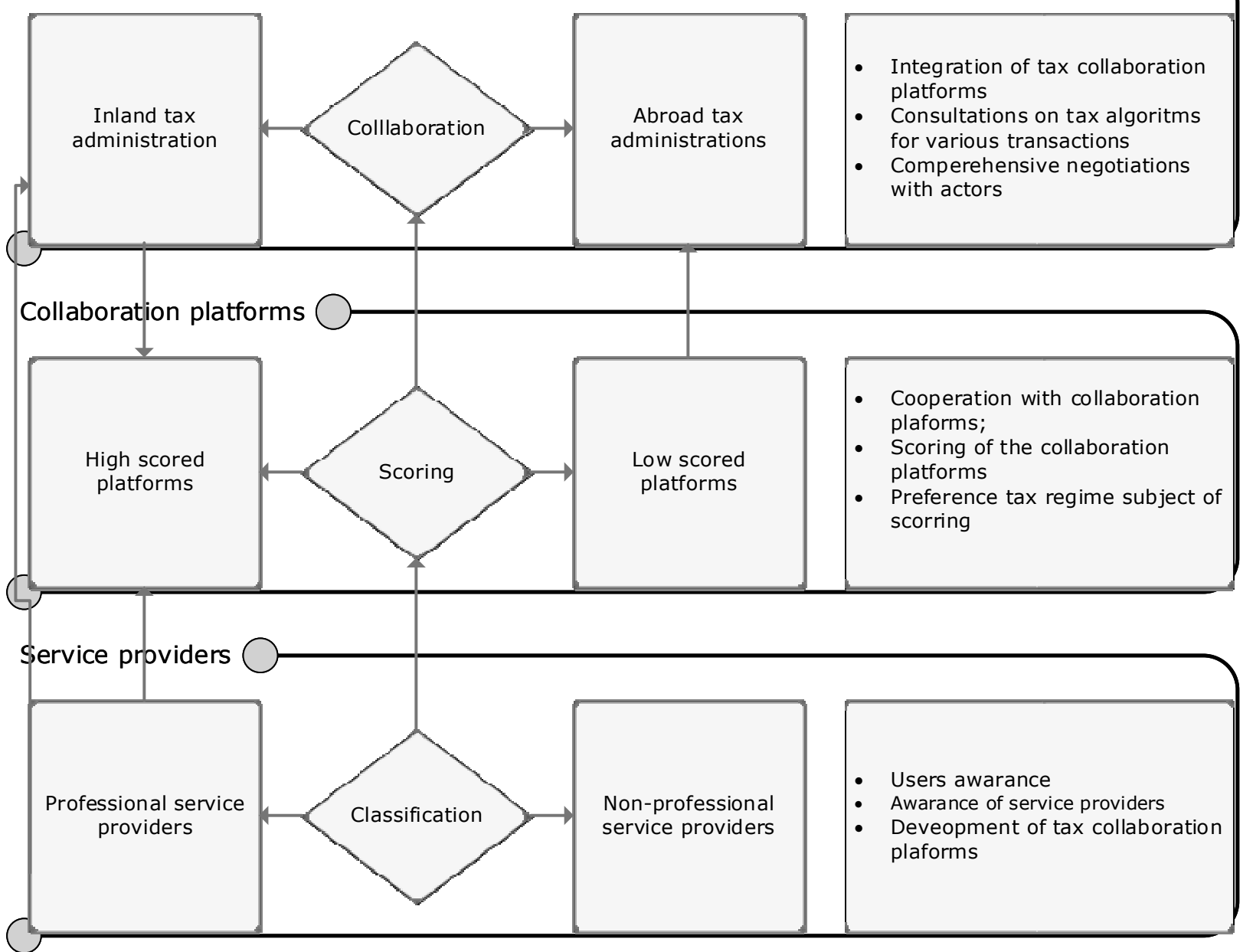

Fig. 4. The model of the tax system development in the collaborative economy

\section{The first level -classification of service providers}

The service providers must be classified as professional (tax payers) and non-professional (nontax payers) service providers. Tax administration must provide clear labelling criteria: number of transactions, annual turnover, business profile and other classification factors that allow to determine the tax regime. These criteria must be traceable allowing the service provider to foresee and predict its "score" in the initial collaborative platform. The tax administrations must care to develop "the tax collaboration platform" that can collect "scores" of the service provider from different collaboration platforms to combine them in the tax declaration.

\section{The second level - scoring of collaboration platforms}

There is an urgent need to set clear guidelines for cooperation between tax administrations and collaborative platforms. The scoring of collaborative platforms may raise a competitive advantage of the tax system of the initial country. The tax administration can provide a preference tax regime for collaboration platforms or/and service providers of high scored collaborated platform to achieve 
service providers favour to the high-scored collaborative platforms, thus initiate an interest of the collaboration platform to cooperate with the tax administrations.

The conditions of collaboration platform scoring may be licensing of "professional" service providers, exchange of information with "the tax collaboration platform”, extending of user profile with taxation details in deals where it used to be in, providing of taxation information for different deals and asking for digital confirmation, providing of tax collection and tax returns.

\section{The third level - collaboration of tax administrations}

The tax administration collaborates with service providers and collaboration platforms, tracing the above-mentioned information and maintaining its own collaboration platform to provide actual taxation details to any "on demand transaction”. Adapted tax regulation applies to non-professional service providers who are granted tax allowances up to a certain threshold from the collaborative economy. The tax administration collaborates with other tax administrations in order to exchange "scores" of registered service providers and collaboration platforms as well as to provide taxation algorithm to any "on-demand transaction."

The investigation of the collaborative economy has shown that effective taxation in this field may be achieved by using collaborative society tools on all levels of the taxation systems. We propose to develop the taxation system in the collaborative economy by some sort of the "gamification": rising awareness of the service providers and the cooperation interest of collaborative platform by using scoring. we also stress the necessity of collaboration among tax administrations.

\section{Research results and discussion}

The proposed integration of the tax administrations into the collaborative economy is a step forward to efficient asset and working time distribution enjoyed in the collaborative economy. An inclusion of service providers in the scoring for tax payer classification is a general action plan for introducing clear boundaries between professional and non-professional service providers in the upto-date manner.

However, similar scoring criteria cannot be extrapolated to all service providers. For instance, hotels are subject to requirements such as licensing, periodic health and safety inspections (Murphy, 2016), these requirements are not identical to the dwellings rented on a collaborative platform. Regarding the transport sector, the variations may cover having of the license, technical inspection of the car etc. The developed "collaborative model' among tax administrations, service providers and collaborative platforms calls for the extensive awareness of the tax administration and policy makers in new development of economy.

With the rapid change and development of technology, the adaptation of the relevant regulation is lagging as never, namely the social drive that allows people to learn new technologies in their daily lives. It is, therefore, up to the responsible national authorities to put in place a regulatory framework that is appropriate to economic reality and not vice versa, subjecting it to the outdated (Rigaux, 2016).

\section{Conclusions, proposals, recommendations}

The aim of the present research was to examine factors that determine an effective taxation in the collaborative economy and to propose a new model of the tax system development. This study has identified, that:

1) the number of collaborative platforms, service providers and users is likely to continue rapidly increase in the next decade; 
2) the significant differences stated between the taxation conditions in traditional un collaborative economies (uncertainty in tax regime of tax payers, huge scale of miserable transactions, unpredictability of residency of collaborative platforms) call for changes in the taxation systems;

3 ) the existing state of play outlines a critical role of users and service providers' awareness;

4) there is a strong need to combat the territorial fragmentation of the taxation;

5) there is No common approach to deal with tax issues at EU level, were some practices are progressive compared to other member states with No specific measures dedicated at all;

6) the development of common integrated tax system at EU level would have positive impact on member state's tax budget.

Therefore, continued efforts are needed to make tax systems in the collaborative economy more effective. The results of the study suggest that the effective solution of the tax system development is to bring it towards the collaboration economy by the integration of tax administration in collaborative society on three levels: service providers, collaborative platforms and tax administrations and using of the tools that are accepted in this field. The findings of this study have several important implications for future practice:

- experimental investigations are needed to estimate efficient scoring criteria;

- a cross-national cooperation of the tax administrations is required to ensure effectiveness of taxation process without physical boundaries;

- A greater focus on academic programmes for tax administrators could raise awareness of the tax administrators and service providers allowing advanced view dealing with the collaborative platforms.

\section{Bibliography}

1. Bozdoganoglu, B. (2017). Tax issues arise from a new economic model: sharing economy. International journal of business and social science. Volume 8. Number 8. Pp 119-135. Retrieved: https://ijbssnet.com/journals/Vol_8_No_8_August_2017/13.pdf. Access.15.11.2018.

2. Botsman, R., Rogers, R. (2010). What's mine is yours: the rise of collaborative consumption. Harper. Business, New York. P.304.

3. Bretta, G. (2018). VAT and the Sharing Economy. World Tax Journal, Volume 10, No.3. pp.1-26.

4. Butenko, A., Larouche, p. (2015). Regulation for innovativeness or regulation of innovation. Tilburg Law and Economics Center (TILEC) Law and Economics Research Paper Series. TILEC Discussion Paper No. 2015007. p.31.

5. Codagnone, C., Biagi F., Abadie F. (2016). The passions and the interests: unpacking the sharing Economy. JRC Science for Policy Report. Retrieved:

http://publications.jrc.ec.europa.eu/repository/bitstream/JRC101279/jrc101279.pdf. Access 15.11.2018.

6. Council of the European Union. (2017). Opinion of European Economic and Social Committee. Taxation of the collaborative economy- analysis of possible tax policies faced with the growth of the collaborative economy. Retrieved: http://data.consilium.europa.eu/doc/document/ST-13925-2017-INIT/en/pdf. Access: 15.11.2018.

7. Karaman, F., Erwin B. (2017). The sharing economy part 2: governments strike back. Insights. Volume 4, No.11. p.11.

8. European Commission. (2016). A European Agenda for the collaborative economy. Retrieved: https://eurlex.europa.eu/legal-content/EN/TXT/?uri=COM \%3A2016 \%3A356 \%3AFIN. Access: 15.11.2018.

9. European Commission. (2018). Study to Monitor the Economic Development of the Collaborative Economy at sector level in the 28 EU Member States. Retrieved: http://www.technopolis-group.com/wpcontent/uploads/2018/08/CE_Final-report_PartA_Final_230218.pdf. Access: 15.11.2018.

10. European Parliament. (2018). The collaborative economy and taxation. Taxing the value created in the collaborative economy. Retrieved:

http://www.europarl.europa.eu/RegData/etudes/IDAN/2018/614718/EPRS_IDA(2018)614718_EN.pdf. Access: 15.11.2018.

11. Goudin, p. (2016). The Cost of Non-Europe in the Sharing Economy. Economic, Social and Legal Challenges and Opportunities. European Parliament Research Service, PE 558.777, January 2016, p.28.

12. Leighton, p. (2016). Professional self-employment, new power and the sharing economy: some cautionary tales from Uber. Journal of Management \& Organization. Volume 22(6). pp.859-874.

13. Maselli, I., Lenaerts, K., Belavy, M. (2016). Five things we need to know about on-demand economy. Centre for European Policy Studies. No 21. Retrieved: 
https://www.ceps.eu/system/files/CEPS \%20Essay \%20No \%2021 \%200n \%20Demand \%20Economy.pdf. Access: 15.11.2018.

14. McClure, R., Lanis. R., Govendir, B. (2016). Analysis of Tax Avoidance Strategies of Top Foreign Multinationals Operation in Australia: An Expose. Retrieved: http://cdn.getup.org.au/1507-Aggressive-TaxAvoidance-By-Top-Foreign-Multinations.pdf. Access 15.11.2018.

15. Murphy, M. (2016). Cities as the Original Sharing Platform: Regulation of the New Sharing Economy. Journal of Business \& Technology Law. Volume 12, Issue 1. p127-149.

16. O'Keefe, B., Jones M. (2015). How Uber plays the tax shell game. Fortune.com, p. N.PAG. Retrieved: http://auth.rtu.Iv/php/redirect.php?goto=http://search.ebscohost.com.resursi.rtu.Iv/login.aspx?direct=true $\& d b=b$ th\&AN $=110478097 \&$ site $=$ ehost-live. Access: 28.11 .2018 .

17. OECD (2017). Shining light on the Shadow economy: Opportunities and Threats. Retrieved: https://www.oecd.org/tax/crime/shining-light-on-the-shadow-economy-opportunities-and-threats.pdf

18. Pantazatou, K. (2018) Taxation of the Sharing Economy in the European Union. Forthcoming, Cambridge Handbook of Law and Regulation of the Sharing Economy, Davidson, Infranca and Finck (eds.), CUP 2018. Retrieved: https://ssrn.com/abstract=3091281. Access 15.11.2018.

19. Petropoulos, G. (2017). An economic review of the collaborative economy. Policy Contribution, issue No 5. Retrieved: http://bruegel.org/wp-content/uploads/2017/02/PC-05-2017.pdf. Access: 15.11.2018.

20. Rahim, N., Lepanjuuri, K., Day, F., Piggott, H., Hudson R., Lubian, K. (2017). Research on the sharing economy. HMRC report 453. Retrieved:

https://assets.publishing.service.gov.uk/government/uploads/system/uploads/attachment_data/file/658728 /HMRC_Report_453_Sharing_Economy.pdf. Access: 15.11.2018

21. Remeur, C. (2018). The collaborative economy and taxation: Taxing the value created in the collaborative economy. EPRS | European Parliamentary Research Service. Retrieved: http://www.europarl.europa.eu/RegData/etudes/IDAN/2018/614718/EPRS_IDA(2018)614718_EN.pdf. Access: 15.11.2018.

22. Rigaux, L. (2016). Sharing Economy: A New Challenge for the Tax Systems in the European States? EMLE Master Thesis, Universitat Hamburg. Retrieved:

https://www.academia.edu/29766860/Sharing_Economy_A_New_Challenge_for_the_Tax_Systems_in_the_ European_States_?auto=download. Access: 15.11.2018

23. Selloni, D. (2017) New Forms of Economies: Sharing Economy, Collaborative Consumption, Peer-to-Peer Economy. In: CoDesign for Public-Interest Services. Research for Development. Springer, Cham.

24. Stanoevska-Slabeva, K., Lenz-Kesekamp, V., Suter, V. (2017). Platforms and the Sharing Economy: An analysis. Report from the EU H2020 Research Project Ps2Share: Participation, Privacy, and Power in the Sharing Economy. p.92.

25.Zale, K. (2016). When Everything is Small: The Regulatory Challenge of Scale in the Sharing Economy (San Diego L. Rev. 949. U of Houston Law Center. No. 2016-A-23. Retrieved:

https://ssrn.com/abstract=2866044. Access 15.11.2018 